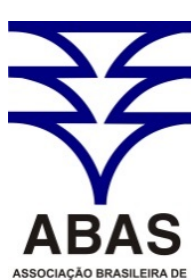

ASSOCIACÁA BRASILERADE www.abas.org

\section{APLICAÇÃO DA ANÁLISE ESTATÍSTICA MULTIVARIADA NO ESTUDO DA QUALIDADE DA ÁGUA SUBTERRÂNEA}

\section{APPLICATION OF MULTIVARIATE STATISTICAL ANALYSIS IN THE STUDY OF THE QUALITY OF GROUNDWATER}

\author{
Maria da Conceição Rabelo Gomes ${ }^{1}$; Itabaraci Nazareno Cavalcante ${ }^{2}$
}

Artigo recebido em: 01/04/2016 e aceito para publicação em: 18/01/2017.

DOI: http://dx.doi.org/10.14295/ras.v31i1.28617

\begin{abstract}
Resumo - A explotação racional e sustentável dos recursos hídricos se torna atualmente cada vez mais importante, tendo em vista que a sociedade convive com diversos e grandes desafios, principalmente aqueles referentes a crescente demanda de água em quantidade e qualidade como consequência do aumento da taxa de crescimento populacional, implantação de indústrias, acréscimo da pegada hídrica, produção de alimentos e, enfim, desenvolvimento, especialmente em áreas de escassez, como em regiões áridas e semiáridas, como no caso específico da área de estudo. Como a utilização das águas subterrâneas para fins diversos também está condicionada a qualidade, neste trabalho desenvolveu-se uma metodologia utilizando a técnica da análise fatorial, associada a análise de agrupamento multivariada, objetivando dar suporte à gestão hidroqualitativa. Foram identificadas similaridades entre atributos físico-químicos capazes de explicar possíveis processos responsáveis pela qualidade das águas, tomando como estudo de caso o município de Fortaleza, Ceará. A análise fatorial aplicada a atributos físico-químicos identificou três componentes responsáveis por aproximadamente $86 \%$ da variância total. O primeiro como indicador de salinidade e poluição $\left(\mathrm{K}^{+}, \mathrm{Ca}^{+2}, \mathrm{Mg}^{2+}, \mathrm{N}^{-N}{ }_{3}\right.$, dureza, condutividade elétrica (CE) e sólidos totais dissolvidos (STD)); o segundo, como indicador de alcalinidade ( $\mathrm{pH}$, bicarbonato e alcalinidade); e o terceiro, como indicador de salinidade $\left(\mathrm{Cl}^{-}, \mathrm{Na}^{+}, \mathrm{CE}\right.$ e STD). A análise de agrupamento multivariada por componente, apresentou três grupos identificados por amostras com diferentes faixas de concentrações.
\end{abstract}

Palavras-chave: Constituintes iônicos. Análise de agrupamento. Poço. Zona litorânea. Nordeste.

Abstract - The rational and sustainable exploitation of water resources is becoming increasingly important, given that society coexists with several major challenges, especially those related to the increasing demand for water in quantity and quality as a consequence of the increase in the rate of growth population growth, the implantation of industries, the increase of the water footprint, food production, and finally, development, especially in areas of scarcity, as in arid and semi-arid regions, as in the case study area. As the use of groundwater for various purposes is also subject to quality, this work developed a methodology using the technique of factor analysis, coupled with multivariate cluster analysis, aiming to support the qualitative management. Similarities were found between physical and chemical properties capable of explaining possible processes responsible for water quality, taking as a case study the city of Fortaleza, Ceará. Factor analysis applied to physical and chemical properties identified three components account for approximately $86 \%$ of the total variance. The first indicator as salinity and pollution $\left(\mathrm{K}^{+}, \mathrm{Ca}^{+2}, \mathrm{Mg}^{2+}, \mathrm{N}-\right.$ $\mathrm{NO}_{3}{ }^{-}$, dureza, $\mathrm{CE}$ and TDS); the second indicator as alkalinity ( $\mathrm{pH}$, bicarbonate, alkalinity); and the third salinity indicator ( $\mathrm{Cl}^{-}, \mathrm{Na}^{+}, \mathrm{CE}$ and TDS). Multivariate analysis grouping component groups identified by forward three samples with different concentration ranges.

Keywords: Ionic constituents. Cluster analysis. Well. Coastal zone. Northeast.

\section{INTRODUÇÃO}

A crescente demanda de água como consequência do aumento da taxa de crescimento populacional, da necessidade de produção de mais alimentos e

\footnotetext{
${ }^{1}$ Universidade Federal do Cariri (UFCa). E-mail: (conceicaorabelo@yahoo.com.br)

${ }^{2}$ Universidade Federal do Ceará (UFC). E-mail: (ita@fortalnet.com.br)
} 
crescimento do setor industrial, além da deterioração qualitativa dos recursos hídricos superficiais, torna a água subterrânea um patrimônio de valor imensurável, capaz de funcionar como reserva estratégica e influenciar decisivamente no desenvolvimento político-socioeconômico de qualquer comunidade (CAVALCANTE, 1998).

O estudo qualitativo das águas subterrâneas tem uma importância considerável, principalmente nas regiões semiáridas do Nordeste brasileiro, onde é necessário resolver o problema da localização e aproveitamento da água em condições de ser utilizada pela população (POHLING et al., 1981). Deve ser considerado que parte da água utilizada para uso doméstico na área de estudo é subterrânea, principalmente aquelas oriundas de chafarizes e que abastecem, principalmente, a população carente de Fortaleza, que recorre a eles por ser uma opção mais econômica que a rede de abastecimento público do estado, porém com alguns poços se encontrando com instalações sanitárias precárias, podendo ocasionar a contaminação da água subterrânea.

Segundo Santos (2008), a qualidade da água subterrânea é avaliada por sua composição e pelo conhecimento dos efeitos que podem causar os seus constituintes.

A análise estatística multivariada é uma ferramenta importante na manipulação e interpretação de dados com muitas variáveis. Através do uso dessa ferramenta é possível agrupar variáveis similares, investigar a dependência entre variáveis agrupadas, relacionar variáveis observadas objetivando predizer uma ou mais variável, além de construir testes de hipóteses (FERREIRA, 1996).

Segundo Hair et al. (2005), este tipo de análise permite reduzir a informação contida em um número de variáveis originais em um conjunto menor de variáveis estatísticas (fatores) com perda mínima de informação. Possibilita, ainda, identificar as variáveis que são responsáveis pela dispersão das observações e evidenciar possíveis agrupamentos, de acordo com seu grau de similaridade ou dissimilaridade (ANDRADE et al., 2003; ANDRADE, 2010; FERNANDES, 2010; SALGADO et al., 2011). Por meio das componentes principais, é possível selecionar aquelas características de maior participação em cada componente e definir as características físico-químicas da água que deverão ser monitoradas reduzindo-se, assim, os custos com análises de características de menor importância na qualidade das águas.

Pelos resultados obtidos em diversas pesquisas, a mesma se apresenta como uma eficiente ferramenta em estudos na qualidade da água subterrânea (VIDAL e KIANG, 2002; BRITO et al., 2006; CLOUTIER et al.; 2008, MACHADO et al., 2008; FERNANDES, 2010; ALMEIDA et al., 2015). Neste sentido, esse trabalho objetiva identificar a similaridade das variáveis determinantes da qualidade das águas subterrâneas no município de Fortaleza identificando possíveis processos hidrogeoquímicos, utilizando a técnica da análise fatorial associada a análise de agrupamento multivariada.

\section{2 ÁREA DE ESTUDO}

A área estudada localiza-se no município de Fortaleza, Ceará, com 314,8 $\mathrm{km}^{2}$, onde $82 \%$ dela é caracterizada pela presença de Aquífero sedimentar (Dunas, Barreiras e Aluvionar) e 18\% pelo Aquífero Fraturado (Cristalino).

O Aquífero Dunas ocorre bordejando a orla da área do município, composta por areias extremamente homogêneas, finas, com diâmetros efetivos de 0,15 a 0,25 mm e espessuras entre 15 a $25 \mathrm{~m}$. Por vezes, ocorrem leitos síltico-argilosos a argilosos, oriundos da própria variação da energia de deposição dos grãos. Geralmente se encontram sobrejacentes à Formação 
Barreiras e o nível estático médio regional é de $6,0 \mathrm{~m}$ e a vazão média obtida a partir de poços tubulares rasos (profundidade inferior a $20 \mathrm{~m}$ ) é de $6,0 \mathrm{~m}^{3} / \mathrm{h}$. O Aquífero Barreiras possui grande variação de fácies, espessura de sedimentos entre 20,0 a 60,0 $\mathrm{m}$ e apresenta intercalações diferenciadas síltico-argilo-arenosos que condicionam a diferentes parâmetros hidrodinâmicos, tanto vertical quanto horizontalmente, com os níveis arenosos representando os principais em termos de vocação aquífera. O Aquífero Aluvionar representa aquíferos livres que ocorrem ao longo das margens dos principais rios de Fortaleza (Cocó, Ceará e Maranguapinho). Os sedimentos aluvionares são geralmente porosos, permeáveis, de pequenas e médias espessuras, com nível estático em torno de 2,0 m e profundidade de poços de até 10,0 m (CAVALCANTE,1998).

No Aquífero Fraturado (não aflorante), os poços tem profundidade predominante de 50,0 a $60,0 \mathrm{~m}$, podendo atingir até $80,0 \mathrm{~m}$; o nível estático localizase entre 1,0 a 15,0 e o rebaixamento do nível d'água entre 5,0 e 35,0 m; a vazão média de $2,0 \quad \mathrm{~m}^{3} / \mathrm{h}$ e a capacidade especifica inferior a 1,00 $\left[\left(\mathrm{m}^{3} / \mathrm{h}\right) / \mathrm{m}\right]$, resultante das diminutas vazões e grandes rebaixamentos do nível d’água (CAVALCANTE,1998).

\section{MATERIAL E MÉTODOS}

O estudo foi desenvolvido a partir dos dados de cinquenta (50) análises físicoquímicas de águas subterrâneas de Fortaleza (Figura 1). Esses dados foram processados no software SPSS Statistics, versão 17.0 .

Os atributos físico-químicos (21) considerados nesta investigação foram: $\mathrm{pH}$, condutividade elétrica (CE), bicarbonato $\left(\mathrm{HCO}_{3}^{-}\right)$, cloretos $\left(\mathrm{Cl}^{-}\right)$, sulfatos $\left(\mathrm{SO}_{4}{ }^{-2}\right)$, sódio $\left(\mathrm{Na}^{+}\right)$, potássio $\left(\mathrm{K}^{+}\right)$, cálcio $\left(\mathrm{Ca}^{+2}\right)$, magnésio $\left(\mathrm{Mg}^{+2}\right)$, ferro total (Fe), alumínio (Al), fluoretos $\left(\mathrm{F}^{-}\right)$, alcalinidade $\left(\mathrm{CaCO}_{3}\right)$, dureza $\left(\mathrm{CaCO}_{3}\right)$, amônia $\left(\mathrm{NH}_{3}\right)$, nitrito $\left(\mathrm{N}-\mathrm{NO}_{2}{ }^{-}\right)$, nitrato $(\mathrm{N}-$
$\mathrm{NO}_{3}{ }^{-}$), turbidez, sólidos totais dissolvidos (STD), sílica $\left(\mathrm{SiO}_{2}\right)$ e fosfato $\left(\mathrm{P}-\mathrm{PO}_{4}{ }^{3-}\right)$.

A análise estatística iniciou com a avaliação do grau de associação entre os atributos, através da Matriz de Correlação de Pearson. Em seguida, aplicou-se a técnica da análise fatorial, buscando se identificar as dimensões de variabilidade comuns (ou fatores) existentes em um conjunto de fenômenos, com o intuito de desvendar estruturas existentes, mas não observáveis diretamente. $\mathrm{Na}$ análise fatorial utilizou-se 0 método das componentes principais, utilizando-se a rotação varimax normalizada objetivando descrever as relações de covariância entre os atributos correlacionados, com base nos fatores identificados, além de evidenciar, por meio de comunalidades, o quanto cada atributo explica cada fator (HOFFMANN, 1992; MANLY, 1998; ARAÚJO et al., 2013). A verificação da adequação dos dados da análise fatorial foi realizada a partir do índice KMO (Kaiser-Meyer-Olkin Measure of Sampling Adequacy) e do Teste Estatístico de Esfericidade de Bartlett, que testa a hipótese nula de que as variáveis analisadas não são correlacionadas (HAIR JR. et al., 1998; ARAÚJO et al., 2013).

Finalizando, realizou-se o agrupamento das amostras a partir do maior número de atributos explicados por um único fator da análise fatorial. Nessa técnica, utilizou-se o método Ward como critério hierárquico de agrupamento, com medida de similaridade dada pela distância euclidiana quadrada (Squared Euclidean DISTANCE). Esse critério hierárquico de agrupamento utiliza a soma total dos quadrados dos desvios de cada objeto em relação à média do grupo onde o mesmo foi inserido. A escolha deste critério se fundamentou na frequente empregabilidade do mesmo em estudos de qualidade da água (VEGA et al., 1998; ANDRADE et al., 2008; YIDANA et al., 2008; FERNANDES, 2010; SALGADO et al., 2011; ALMEIDA e FRISCHKOM, 2015). O agrupamento foi apresentado por meio de um dendrograma e o ponto de 
"corte", utilizado na definição do número de grupos, foi definido na maior variação da distância reescalonada do coeficiente de aglomeração (FERREIRA, 1996).

Os grupos formados pela técnica do agrupamento tiveram suas médias comparadas pelo teste " $t$ ” de Student aos níveis de $5 \%$ e $1 \%$, após execução da análise de variância. Estes testes indicam as variáveis responsáveis pela formação dos grupos na análise multivariada.

A técnica de agrupamento hierárquico interliga as amostras por suas associações, produzindo um dendrograma onde as amostras semelhantes, segundo as variáveis escolhidas, são agrupadas entre si. A suposição básica de sua interpretação é quanto menor a distância entre os pontos, maior a semelhança entre as amostras. Segundo Almeida et al. (2015), os dendrogramas são úteis principalmente na visualização de semelhanças entre amostras ou objetos representados por pontos em espaço com dimensão maior do que três, onde a representação de gráficos convencional não é possível.

Para a classificação iônica das águas subterrâneas utilizou-se o Diagrama de Piper, frequentemente usado para classificar o tipo químico da água de acordo com o conteúdo iônico dominante. O software utilizado foi o Qualigraf, versão 1.17 (MOBUS, 2014) que tem uma interface extremamente simples e otimizada para a classificação das águas.

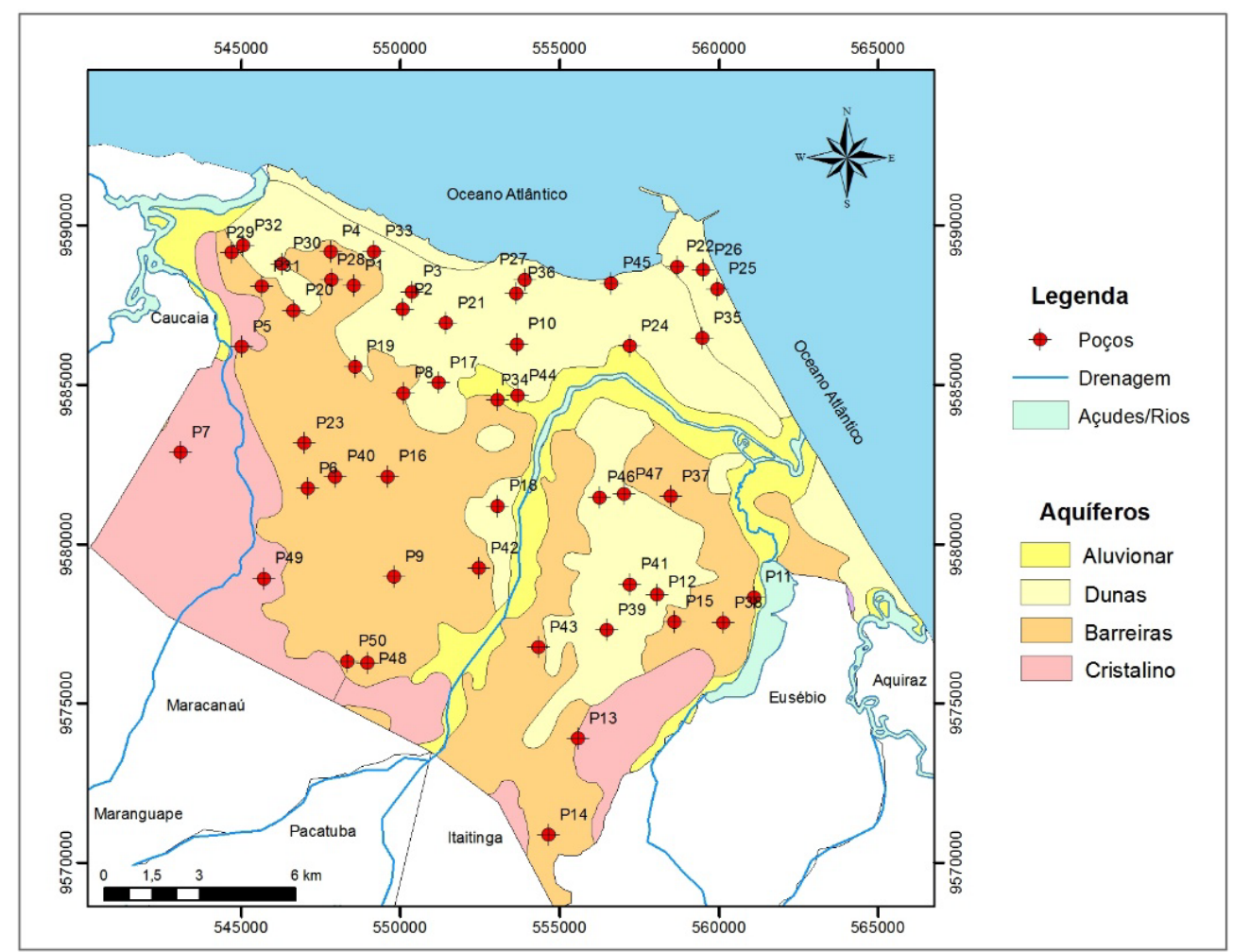

Figura 1 - Distribuição dos poços com análises físico-químicas na área de estudo Figure 1 - Distribution of wells with physical-chemical analysis in the study area Fonte: Elaborado a partir de Gomes (2013).

\section{RESULTADOS E DISCUSSÃO}

Inicialmente, foram utilizados os 21 atributos físico-químicos na análise fatorial. Nesta primeira análise a matriz de correlação apresentou seis atributos
(Alumínio, fluoretos, amônia, nitrito, sílica e fosfato) com baixa correlação $(\leq 0,486)$. $\mathrm{O}$ índice $K M O$ obtido para o conjunto de atributos analisados foi de 0,440 e os Testes Estatísticos de Esfericidade de Bartlett não mostraram-se significativos a 
$\mathrm{p}<0,01$. Esses resultados indicam que os fatores encontrados na Análise Fatorial não descreveram adequadamente a variação dos dados originais. Nesse contexto, os seis (6) dos 21 atributos analisados apresentaram baixa comunalidade (inferior a 0,600 ) e um fator de explicação de apenas $5 \%$ da variação total dos dados.

Os 15 atributos restantes foram utilizados numa segunda simulação, na qual verificou-se que os índices $K M O$ permaneceram baixos e os Testes Estatísticos de Esfericidade de Bartlett continuaram sem significância. Nessa simulação, três (3) dos 15 atributos restantes (Sulfato, ferro e turbidez) continuaram apresentando baixa comunalidade e um fator de explicação de apenas 9\% da variação total dos dados.

Em uma terceira simulação, os atributos que apresentaram baixa comunalidade foram desconsiderados e os modelos apresentaram resultados favoráveis para doze (12) atributos $(\mathrm{pH}$, condutividade elétrica, bicarbonato, cloretos, sódio, potássio, cálcio, magnésio, alcalinidade, dureza, nitrato e sólidos totais dissolvidos), com índice KMO de 0,711 e Testes de Esfericidade de Bartlett significativos a $\mathrm{p}<0,01$.

$\mathrm{Na}$ Tabela 1 encontram-se as matrizes de correlação para os dozes (12) atributos analisados na terceira simulação. Observa-se que dos 66 coeficientes de correlação, $67 \%$ do total, apresentaram valores significativos. Destes, cerca de $31 \%$ encontram-se no intervalo $0,6 \leq|\mathrm{r}|<$ 0,9 , caracterizados, segundo CallegariJacques (2003), como de correlação forte. Os restantes (69\%) encontram-se no intervalo $0,3 \leq|r|<0,6$, caracterizados como de correlação moderada.

A matriz de correlação (Tabela 1) mostra que a $\mathrm{CE}$ possui correlação forte com o cloreto, sódio, cálcio, magnésio, dureza e nitrato, indicando possível influência desses íons no aumento da salinidade das águas na área. A correlação observada entre o magnésio e a dureza era esperada, uma vez que a dureza é definida pela maior ou menor presença de sais dissolvidos de cálcio e magnésio. $\mathrm{O} \mathrm{NO}_{3}{ }^{-}$ apresentou correlação forte com CE e $\mathrm{K}^{+}$, indicando uma possível relação destes íons com fontes de poluição de origem orgânica. $\mathrm{O}$ pH apresenta uma forte correlação com o bicarbonato e alcalinidade e indica a condição de acidez, alcalinidade ou neutralidade da água e que pode influenciar em vários processos biológicos e químicos nos corpos d'água. Segundo Pina (2012), existe uma forte relação entre o pH da água e a concentração do gás carbônico, dos bicarbonatos e dos carbonatos ( $\mathrm{pH}<8,3$, ausência de $\mathrm{CO}_{3}{ }^{-2}$ ).

Os resultados da análise fatorial apresentaram três fatores, com autovalores superiores a um (Tabela 2). O primeiro fator apresentou uma contribuição para explicação da variância total dos atributos de aproximadamente $49 \%$, o segundo de $25 \%$ e o terceiro de $11 \%$. Estes resultados indicam que os três fatores respondem por aproximadamente $86 \%$ da variância total dos dados.

O primeiro fator apresentou uma contribuição para explicação da variância total do conjunto amostral de aproximadamente 49\%, mostrando uma alta correlação entre os atributos potássio, cálcio, magnésio, dureza, nitrato, CE e STD. As variáveis com maiores cargas fatoriais, nesse fator, foram magnésio $(0,776)$, cálcio $(0,863)$ e dureza $(0,944)$, embora as demais variáveis também apresentem forte relação com esse fator, dados os elevados valores das cargas fatoriais e das comunalidades, sendo que essas representam o quanto da variância da variável é reproduzida pelos fatores comuns (Tabela 2). 
Tabela 1 - Matriz de correlação dos atributos físico-químicos das águas subterrâneas

Table 1 - Correlation matrix of physico-chemical characteristics of groundwater

\begin{tabular}{|c|c|c|c|c|c|c|c|c|c|c|c|c|}
\hline Atributo & pH & $\mathrm{CE}$ & HCO & Cl & $\mathrm{Na}$ & $\mathbf{K}$ & Ca & Mg & Alcal. & $\mathrm{NO}_{3}$ & Dur. & STD \\
\hline $\mathrm{pH}$ & 1,000 & & & & & & & & & & & \\
\hline $\mathrm{CE}$ & 0,002 & 1,000 & & & & & & & & & & \\
\hline HCO & 0,698 & 0,231 & 1,000 & & & & & & & & & \\
\hline $\mathrm{Cl}$ & $-0,156$ & $0,861 *$ & 0,031 & 1,000 & & & & & & & & \\
\hline $\mathrm{Na}$ & 0,159 & $0,722 *$ & 0,340 & $0,765^{*}$ & 1,000 & & & & & & & \\
\hline K & $-0,257$ & 0,591 & $-0,119$ & 0,437 & 0,206 & 1,000 & & & & & & \\
\hline $\mathrm{Ca}$ & 0,272 & $0,638 *$ & 0,344 & 0,353 & 0,163 & 0,458 & 1,000 & & & & & \\
\hline $\mathrm{Mg}$ & $-0,047$ & $0,646^{*}$ & 0,035 & $0,606 *$ & 0,274 & 0,487 & 0,521 & 1,000 & & & & \\
\hline Alcal. & $0,701^{*}$ & 0,226 & $0,999 *$ & 0,023 & 0,336 & $-0,119$ & 0,345 & 0,038 & 1,000 & & & \\
\hline Dur. & 0,148 & $0,734 *$ & 0,235 & 0,533 & 0,243 & 0,539 & $0,900^{*}$ & $0,841 *$ & 0,238 & & 1,00 & \\
\hline $\mathrm{NO}_{3}$ & $-0,389$ & $0,697 *$ & $-0,232$ & 0,554 & 0,279 & $0,669 *$ & 0,479 & 0,565 & $-0,235$ & 1,000 & 0,592 & \\
\hline STD & 0,157 & $0,949 *$ & 0,439 & $0,783 *$ & $0,745^{*}$ & 0,552 & $0,693^{*}$ & $0,631 *$ & 0,435 & $0,761^{*}$ & $0,625^{*}$ & 1,00 \\
\hline
\end{tabular}

Legenda: $\mathrm{pH}$ - potencial hidrogeniônico; $\mathrm{CE}(\mu \mathrm{S} / \mathrm{cm})$ - condutividade elétrica; $\mathrm{HCO}(\mathrm{mg} / \mathrm{L})$ - bicarbonato; $\mathrm{Cl}$ (mg/L) - cloretos; Na (mg/L) - sódio; K (mg/L) - potássio; Ca (mg/L) - cálcio; Mg (mg/L) - magnésio; Alcal (mg/L) - alcalinidade; Dur (mg/L) - dureza total; $\mathrm{NO}_{3}(\mathrm{mg} / \mathrm{L})$ - nitrato; STD (mg/L) - sólidos totais dissolvidos. * correlações fortes.

O segundo fator corresponde a $25 \%$ de toda a variância do conjunto amostral, mostrando uma alta correlação entre $\mathrm{pH}$, bicarbonato e alcalinidade e incluiu variáveis com altos valores de comunalidades, chegando até 92,50\% (Tabela 2).

O terceiro fator é representado por $11 \%$ de toda a variância do conjunto amostral, mostrando uma alta correlação entre cloreto, sódio, CE e STD, com elevadas cargas fatoriais variando de 0,846 (sódio) a 0,948 (cloreto) e também com altos valores de comunalidades (Tabela 2).

Em função das maiores cargas fatoriais das variáveis que compõem os três fatores as 12 variáveis de qualidade das águas podem ser representadas por: Fator 1 - componente de salinidade (mineralização) e atividades antrópicas (contaminação com elementos nitrogenados); Fator 2 - componente de alcalinidade e Fator 3 - componente de salinidade (presença de aerossóis marinhos, composto, principalmente, por
$\mathrm{NaCl})$. Essas variáveis são determinantes na caracterização da qualidade das águas subterrâneas.

A técnica de análise de agrupamento multivariada, aplicada aos atributos explicados pelos fatores 1, 2 e 3 da análise fatorial, agrupou as amostras com características semelhantes, ou seja, com águas quimicamente similares (Figuras 2, 3 e 4). Os grupos obtidos e os atributos que os geraram foram submetidos à análise de variância One-Way ANOVA e apresentaram níveis de significância inferiores a 5\%, indicando a formação de um conjunto relativamente estável de grupos.

O número de grupos foi definido pela primeira grande diferença entre os coeficientes reescalonados de agrupamento. Esses coeficientes explicitaram o ponto de corte cinco, onde observou-se a formação de três grupos homogêneos para cada fator. 
Tabela 2 - Cargas fatoriais, comunalidades e variância explicada na análise fatorial dos 12 atributos analisados, após a rotação pelo método varimax

Table 2 - Factorial loads, communalities and explained variance in the factor analysis of the 12 attributes analyzed, after rotation by varimax method

\begin{tabular}{|c|c|c|c|c|}
\hline \multirow[b]{2}{*}{ Atributo } & \multicolumn{3}{|c|}{ Carga Fatorial } & \multirow[b]{2}{*}{$\begin{array}{c}\text { Comunalidade } \\
0,763\end{array}$} \\
\hline & $\begin{array}{l}\text { Fator } 1 \\
-0,018\end{array}$ & $\begin{array}{c}\text { Fator } 2 \\
\mathbf{0 , 8 7 0}\end{array}$ & $\begin{array}{l}\text { Fator } 3 \\
-0,081\end{array}$ & \\
\hline CE & 0,647 & 0,081 & 0,729 & 0,956 \\
\hline $\mathrm{HCO}$ & 0,052 & 0,943 & 0,176 & 0,924 \\
\hline $\mathrm{Cl}$ & 0,403 & $-0,117$ & 0,846 & 0,892 \\
\hline $\mathrm{Na}$ & 0,041 & 0,218 & 0,948 & 0,949 \\
\hline $\mathrm{K}$ & 0,692 & $-0,271$ & 0,242 & 0,610 \\
\hline $\mathrm{Ca}$ & 0,863 & 0,348 & 0,035 & 0,868 \\
\hline $\mathrm{Mg}$ & 0,776 & $-0,042$ & 0,270 & 0,677 \\
\hline Alcal & 0,055 & 0,945 & 0,168 & 0,925 \\
\hline Dur. & 0,944 & 0,198 & 0,160 & 0,955 \\
\hline $\mathrm{NO}_{3}$ & 0,707 & $-0,395$ & 0,362 & 0,788 \\
\hline STD & 0,646 & 0,286 & 0,692 & 0,978 \\
\hline Variância explicada (\%) & 49,214 & 25,165 & 11,331 & \\
\hline Variância acumulada (\%) & & 85,71 & & \\
\hline
\end{tabular}

Legenda: $\mathrm{pH}$ - potencial hidrogeniônico; $\mathrm{CE}(\mu \mathrm{S} / \mathrm{cm})$ - condutividade elétrica; HCO (mg/L) bicarbonato; Cl (mg/L) - cloretos; Na (mg/L) - sódio; K (mg/L) - potássio; Ca (mg/L) - cálcio; $\mathrm{Mg}(\mathrm{mg} / \mathrm{L})$ - magnésio; Alcal (mg/L) - alcalinidade; Dur (mg/L) - dureza total; $\mathrm{NO}_{3}(\mathrm{mg} / \mathrm{L})$ nitrato; STD (mg/L) - sólidos totais dissolvidos.

De acordo com os atributos do fator $1\left(\mathrm{~K}^{+}, \mathrm{Ca}^{+2}, \mathrm{Mg}^{2+}, \mathrm{N}-\mathrm{NO}_{3}{ }^{-}\right.$, dureza, $\mathrm{CE}$ e STD) (Figura 2) foram gerados 3 grupos similares, composto por 34\% (17 poços), $20 \%$ (10 poços) e $46 \%$ (23 poços) das amostras analisadas nos Grupos 1, 2 e 3, respectivamente.

O Grupo 1 (17 poços) é caracterizado por águas de salinidade intermediária (Figura 2), com CE entre 464 e $628 \mu \mathrm{S} / \mathrm{cm}$. Os Sólidos Totais Dissolvidos oscilaram de 276 a $401 \mathrm{mg} / \mathrm{L}$, estando, todas as amostras dentro do limite permitido (1000 mg/L) para águas potáveis para consumo humano conforme a Portaria $n^{\circ}$ 2914/2011 do Ministério da Saúde (MS). A dureza total das amostras atingiu no máximo $160 \mathrm{mg} / \mathrm{L}$, estando também dentro do limite permitido (500 mg/L) pela Portaria vigente. Em relação aos íons potássio, cálcio e magnésio, a Portaria no 2914/2011 do MS
(BRASIL, 2011) não estabelece um valor máximo permissível para suas concentrações. As concentrações médias de potássio, cálcio e magnésio foram de 7, 16 e $17 \mathrm{mg} / \mathrm{L}$. Das dezessete (17) amostras de águas dos poços, seis amostras (35\%) não atendem aos padrões de potabilidade, quanto ao íon ${\mathrm{N}-\mathrm{NO}_{3}}^{-}$, variando de 0,9 a 18 $\mathrm{mg} / \mathrm{L}$ de $\mathrm{N}$-nitrato, nos setores sul e norte da área, respectivamente, refletindo o efeito das ações antrópicas pela concentração populacional ao longo dos bairros.

O Grupo 2 (10 poços) apresenta baixas concentrações de sais e detém águas de melhor qualidade (Figura 2). São águas que atendem aos padrões de potabilidade quanto a concentração de STD, dureza e nitrato. A CE variou de 234 e $443 \mu \mathrm{S} / \mathrm{cm}$. Os Sólidos Totais Dissolvidos oscilaram de 130 a $294 \mathrm{mg} / \mathrm{L}$. A dureza total das 
amostras atingiu no máximo $92 \mathrm{mg} / \mathrm{L}$. As concentrações dos íons potássio, cálcio e magnésio foram de 4,6 e $10 \mathrm{mg} / \mathrm{L}$. O nitrato variou de 0,7 a $10 \mathrm{mg} / \mathrm{L}$, nos setores centro e norte da área, respectivamente.

O Grupo 3 (23 poços) é composto por altas concentrações de sais e qualidade das águas inferior aos demais grupos (Figura 2). São águas que não atendem aos padrões de potabilidade quanto a concentração de nitrato. $74 \%$ (17 poços) das águas analisadas não atendem aos padrões de potabilidade, quanto ao íon $\mathrm{N}-\mathrm{NO}_{3}{ }^{-}$, atingindo até $39 \mathrm{mg} / \mathrm{L}$ de $\mathrm{N}$-nitrato, nas porções nordeste e noroeste da área, mostrando que a ação antrópica é determinante para a qualidade da água na

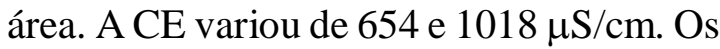
Sólidos Totais Dissolvidos oscilaram de 366 a $754 \mathrm{mg} / \mathrm{L}$. A dureza total das amostras atingiu no máximo $240 \mathrm{mg} / \mathrm{L}$. As concentrações dos íons potássio, cálcio e magnésio foram de 15, 32 e $22 \mathrm{mg} / \mathrm{L}$, respectivamente.

De acordo com os atributos do fator $2\left(\mathrm{pH}, \mathrm{HCO}_{3}^{-}\right.$e alcalinidade) (Figura 3) foram gerados 3 grupos similares, composto por $46 \%$ (23 poços), $40 \%$ (20 poços) e $14 \%$ ( 7 poços) das amostras nos Grupos 1, 2 e 3, respectivamente.

Os poços que compõem o Grupo 1 apresentaram uma maior similaridade
(Figura 3) dos atributos investigados e qualidade das águas inferior em relação aos Grupos 2 e 3. São caracterizadas por águas ácidas (100\% das amostras), variando de 4,5 a 6,3, onde apenas $13 \%$ (3 poços) das águas estão dentro do limite permitido $(6,0$ a 9,5) pela Portaria $n^{0}$ 2914/2011 do Ministério da Saúde. Segundo Hounslow (1995), a principal razão dos valores de $\mathrm{pH}$ da água serem inferiores a 6 é a quantidade significativa de minerais de argila; que dissolve e libera sílica e alumínio anormalmente alta para a água. Além da alcalinidade, o pH é essencialmente uma função do gás carbônico dissolvido $\left(\mathrm{CO}_{2}\right)$ e dos ácidos orgânicos disponíveis nos solos que aumentam a acidez das águas subterrâneas e a capacidade de dissolver Fe e Mg. Apresentaram as menores concentrações de alcalinidade (20 mg/L) e bicarbonato (24 mg/L) nas águas em relação aos Grupos 2 e 3 . Os baixos valores $(<6)$ de $\mathrm{pH}$ encontrados nas águas desses poços provavelmente estão associados as águas do Aquífero Barreiras, resultando assim, em reações de equilíbrio entre a água e o meio geológico, e também pela introdução de águas recentes no aquífero (águas de chuva), com concentrações mais elevadas de $\mathrm{CO}_{2}$, promovendo a diminuição do pH e aumentando, assim, a acidez das águas subterrâneas. 


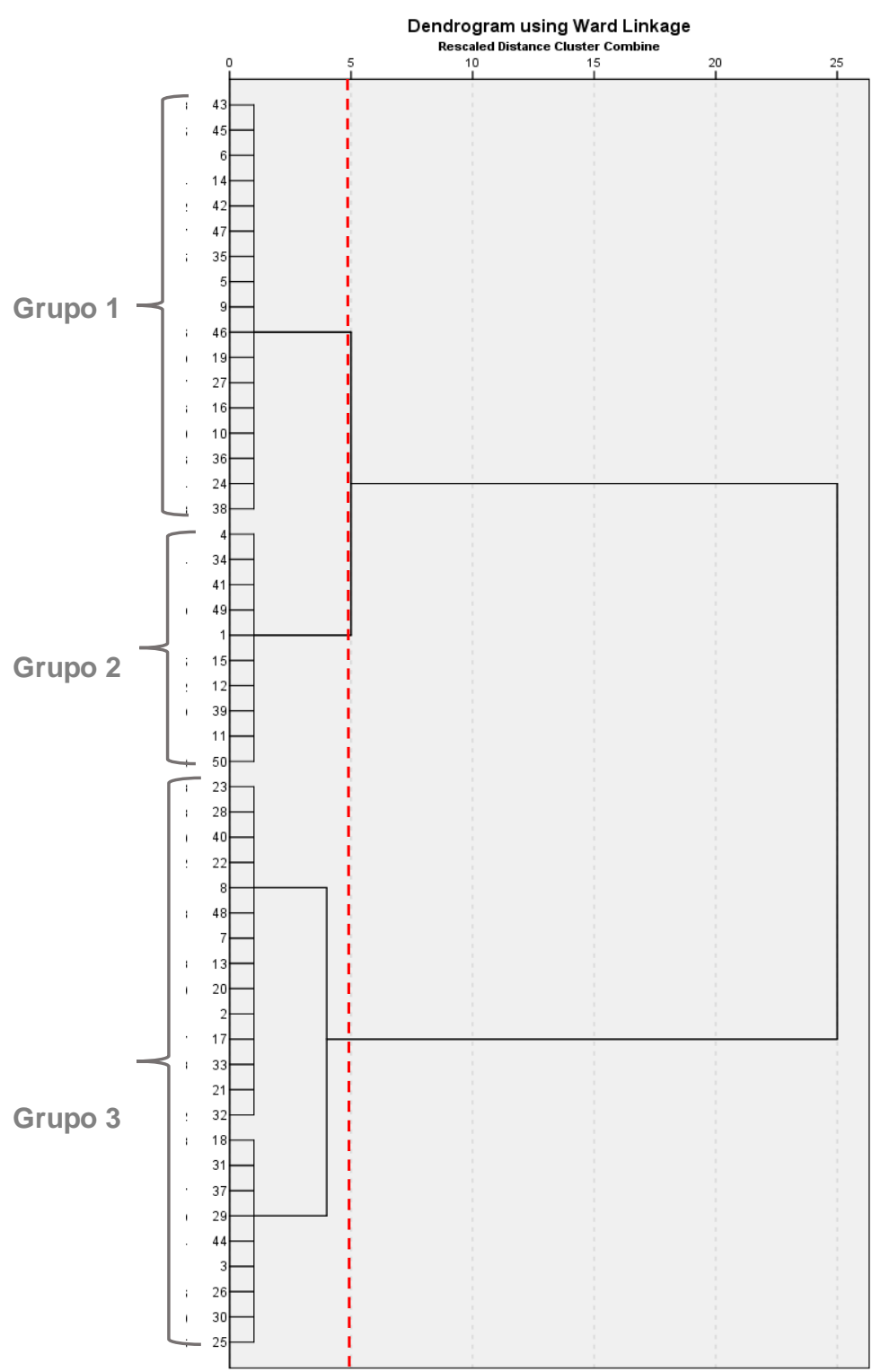

Figura 2 - Dendrograma resultante da Análise de Agrupamento das variáveis explicadas pelo fator 1 da Análise Fatorial

Figure 2 - Dendrogram resulting from the variable Cluster Analysis explained by factor 1 Factorial Analysis

O Grupo 2 (20 poços) apresentou uma maior heterogeneidade quando comparado ao primeiro grupo (Figura 3). Há predominância também de águas ácidas (85\% das amostras). São águas com $\mathrm{pH}$, variando de 5,9 a 7,4 , onde $95 \%$ (19 poços) das águas analisadas estão dentro do limite permitido $\left(6,0\right.$ a 9,5) pela Portaria $\mathrm{n}^{0}$ 2914/2011 do Ministério da Saúde para águas de consumo humano. Segundo Hounslow (1995), os valores mais elevados de $\mathrm{pH}$ geralmente se encontram em águas com predominância dos íons $\mathrm{Na}^{+}$e $\mathrm{Ca}^{++}$ou em águas ricas em bicarbonatos; as águas poluídas geralmente são mais ácidas. As concentrações de alcalinidade e bicarbonato variam em média de 66 a $81 \mathrm{mg} / \mathrm{L}$, respectivamente.

No Grupo 3 (7 poços) se constou a maior concentração de águas básicas (29\%) quando comparado ao segundo grupo (15\%) (Figura 3). São águas com $\mathrm{pH}$, variando de 5,3 a 8,4 , onde $86 \%$ (6 poços) das águas analisadas estão dentro do 
limite permitido $\left(6,0\right.$ a 9,5) pela Portaria $n^{0}$ 2914/2011 do Ministério da Saúde. Apresentaram as maiores concentrações de alcalinidade e bicarbonato, com média de 135 a $161 \mathrm{mg} / \mathrm{L}$, respectivamente. Em geral, as águas de $\mathrm{pH}$ baixo tendem a ser corrosivas ou agressivas a determinados materiais (superfícies de cimento-amianto, por exemplo), enquanto que as águas de alto $\mathrm{pH}$ tendem a formar incrustações e, além disso, com pH ácido também podem causar doenças como gastrite, câncer gástrico e restrições nos usos gerais de indústrias.

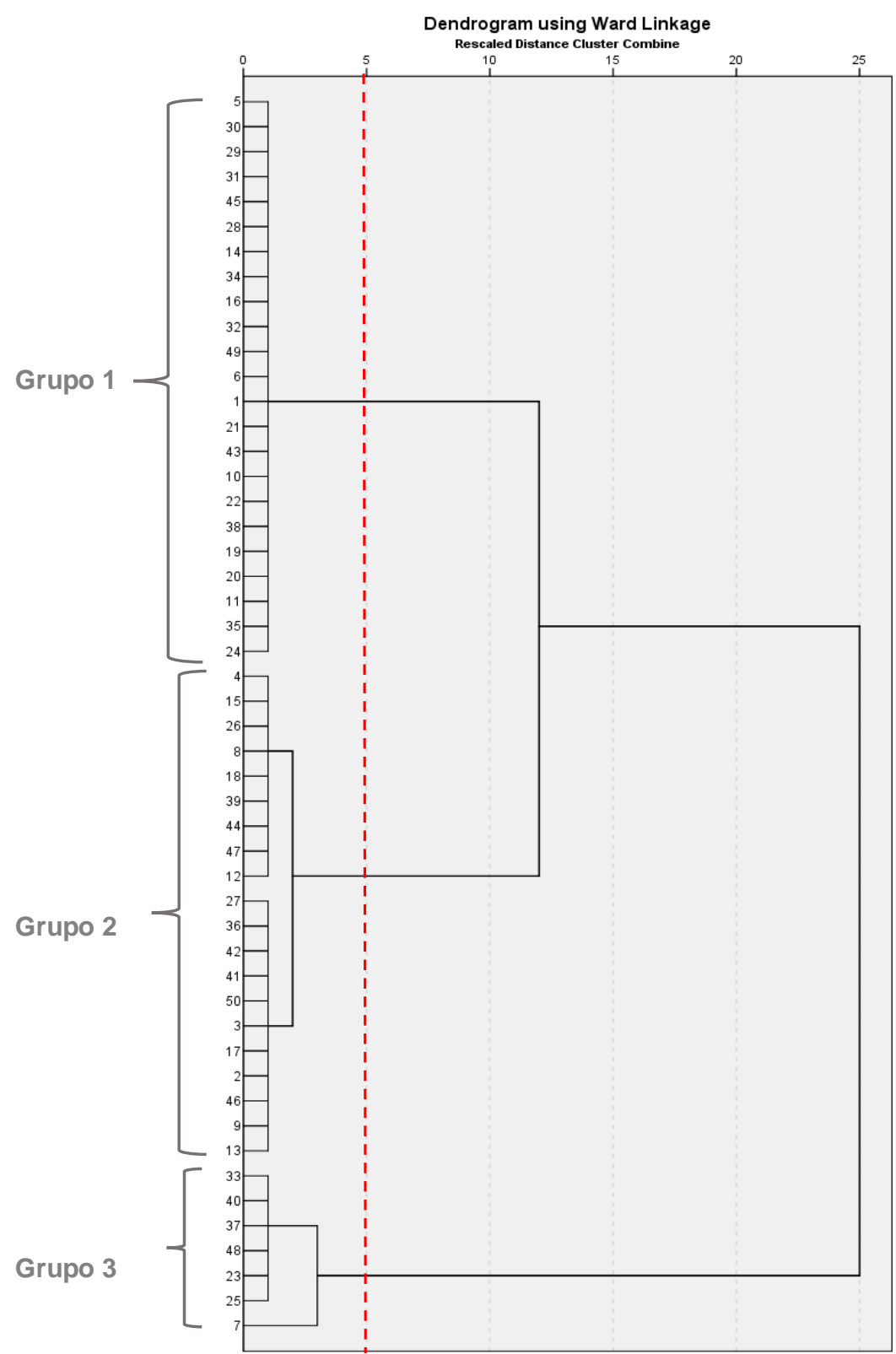

Figura 3 - Dendrograma resultante da Análise de Agrupamento das variáveis explicadas pelo fator 2 da Análise Fatorial

Figure 3 - Dendrogram result of Cluster Analysis of the variables explained by factor 2 Factorial Analysis 
De acordo com os atributos do fator 3 ( $\mathrm{Cl}^{-}, \mathrm{Na}^{+}$, CE e STD), (Figura 4) foram gerados também 3 grupos similares, composto por $26 \%$ (13 poços), $28 \%$ (14 poços) e $46 \%$ ( 23 poços) das amostras nos Grupos 1, 2 e 3, respectivamente.

O Grupo 1 (13 poços) é caracterizado por águas de salinidade intermediária (Figura 4), com CE entre 511 e $628 \mu \mathrm{S} / \mathrm{cm}$. Os Sólidos Totais Dissolvidos oscilaram de 289 a $401 \mathrm{mg} / \mathrm{L}$, estando, todas as amostras dentro do limite permitido (1000 mg/L) pela Portaria ${ }^{0}$ 2914/2011 do Ministério da Saúde (MS). O cloreto oscilou de 90 a $154 \mathrm{mg} / \mathrm{L}$, estando dentro do limite permitido (250 $\mathrm{mg} / \mathrm{L})$ pela Portaria vigente. O sódio variou de 35 a $90 \mathrm{mg} / \mathrm{L}$, e de acordo com a Portaria ${ }^{\circ}$ 2914/2011 do Ministério da Saúde está também dentro do limite permitido (200 mg/L). Segundo Cavalcante (1998), o cloreto pode estar associado à influência das águas marinhas sobre as continentais, já que a área encontra-se localizada na zona litorânea, ou à captação das águas subterrâneas no meio cristalino, tendo em vista que os cloretos são provenientes da lixiviação de minerais ferromagnesianos de rochas ígneas ou, ainda, a uma fonte de poluição antrópica rica em cloretos e que possa estar cedendo-os para as águas subterrâneas.

O Grupo 2 (14 poços) apresenta baixas concentrações de sais (Figura 4). A CE variou de 234 e $502 \mu \mathrm{S} / \mathrm{cm}$. Os Sólidos Totais Dissolvidos oscilaram de 130 a 313 $\mathrm{mg} / \mathrm{L}$. O cloreto oscilou de 26 a $126 \mathrm{mg} / \mathrm{L}$ e o sódio de 27 a $78 \mathrm{mg} / \mathrm{L}$, estando todos os atributos de acordo com o valor máximo permitido pela Portaria ${ }^{0}$ 2914/2011 do Ministério da Saúde, que é de 1000, 250 e
200 mg/L para STD, cloreto e sódio, respectivamente. Os valores considerados mais baixos da $\mathrm{CE}$ devem-se às pequenas concentrações dos constituintes em solução, que são resultantes do material geológico sedimentar, constituída de sedimentos clásticos de origem continental, de composição predominantemente quartzosa, através dos quais a água subterrânea circula, bem como a elevada pluviosidade, característica do clima da área.

Os poços do Grupo 3 apresentam altas concentrações de sais e também atendem aos padrões de potabilidade quanto a concentração de cloreto, sódio e STD (Figura 4). A CE variou de 654 e 1018 $\mu \mathrm{S} / \mathrm{cm}$. Os Sólidos Totais Dissolvidos oscilaram de 366 a $754 \mathrm{mg} / \mathrm{L}$. O cloreto oscilou de 84 a $228 \mathrm{mg} / \mathrm{L}$ e o sódio de 55 a $145 \mathrm{mg} / \mathrm{L}$. Esse grupo são os mesmos poços do fator 1 (Grupo 3). A ocorrência de maiores concentrações de águas cloretadas na área está potencialmente relacionada às águas marinhas e pluviais, geologia (meio cristalino) ou fonte de poluição que favorece a concentração do mesmo nas águas subterrâneas. A ocorrência das maiores concentrações de sódio nas águas é resultante de elevadas concentrações de bicarbonato e, consequentemente, há redução do cálcio e magnésio na solução do solo. Os valores mais elevados de CE podem estar associados, pontualmente, as maiores concentrações de íons principalmente de cloretos. O aumento de STD depende das condições climáticas, onde as maiores concentrações de sais ocorrem na estiagem. 


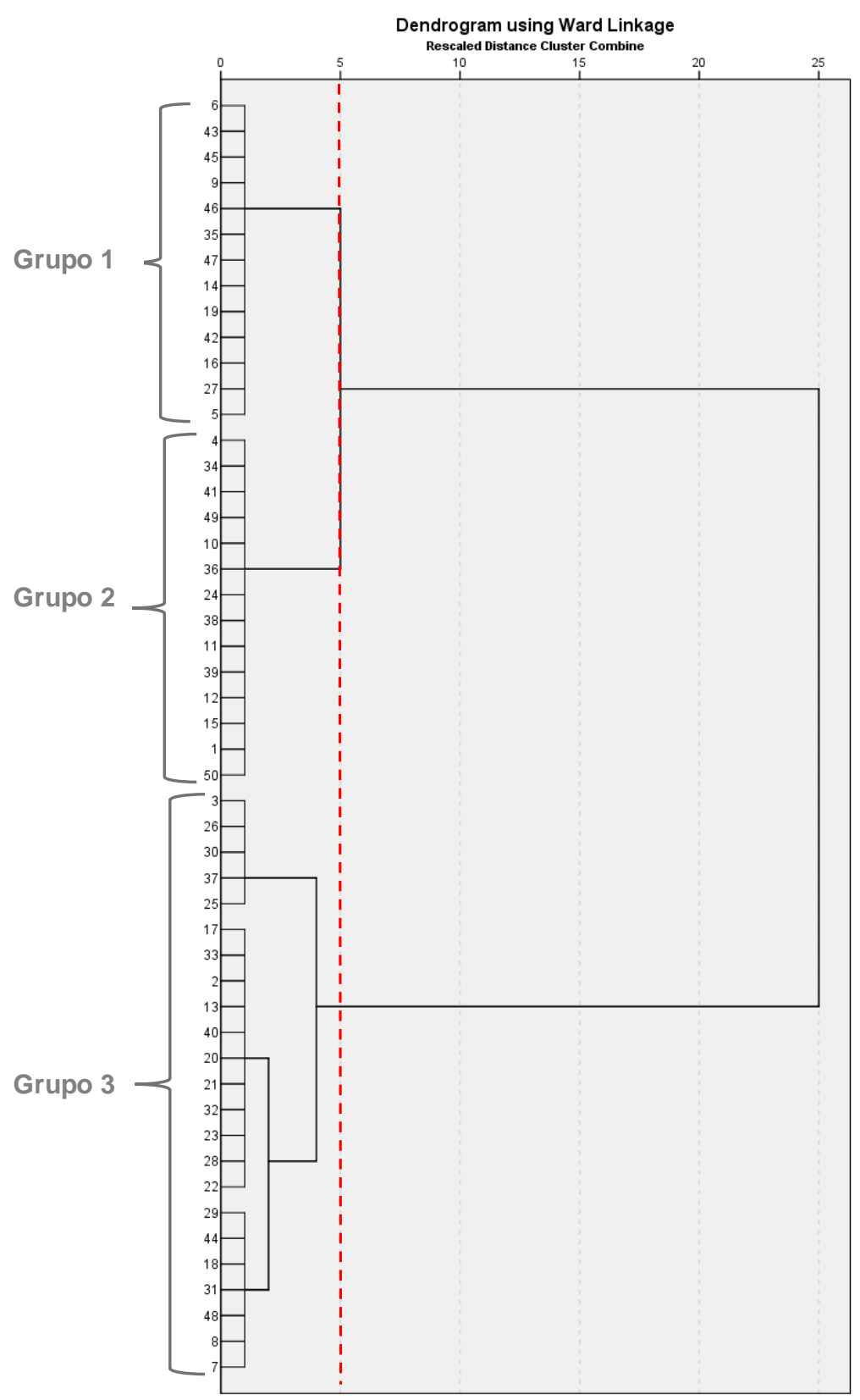

Figura 4 - Dendrograma resultante da Análise de Agrupamento das variáveis explicadas pelo fator 3 da Análise Fatorial

Figura 4 - Dendrograma resultante da Análise de Agrupamento das variáveis explicadas pelo fator 3 da Análise Fatorial

De acordo com a classificação iônica (Figura 5), tem-se a predominância de águas Cloretadas (84\%) Sódicas (74\%), seguidas das Mistas (14\%) e Mistas (26\%) e apenas 2\% águas Bicarbonatadas. As águas subterrâneas da área são caracterizadas por águas Cloretadas Sódicas, tendo $50 \%$ do ânion cloreto $\left(\mathrm{Cl}^{-}\right)$ sobre os demais. Esta predominância (84\%) está relacionada às águas marinhas, aerossóis e à evaporação, que aumentam a concentração do cloreto nas águas subterrâneas, favorecida pela proximidade da área de pesquisa ao Oceano Atlântico, inserida na faixa costeira. Segundo Gomes (2013), a concentração do cloreto se deve 
às suas propriedades químicas, como alta solubilidade, baixa precipitação e raio iônico. A predominância dos constituintes iônicos ( $\mathrm{Na}$ e $\mathrm{Cl}$ ) nas águas subterrâneas é independente do período de recarga do aquífero.

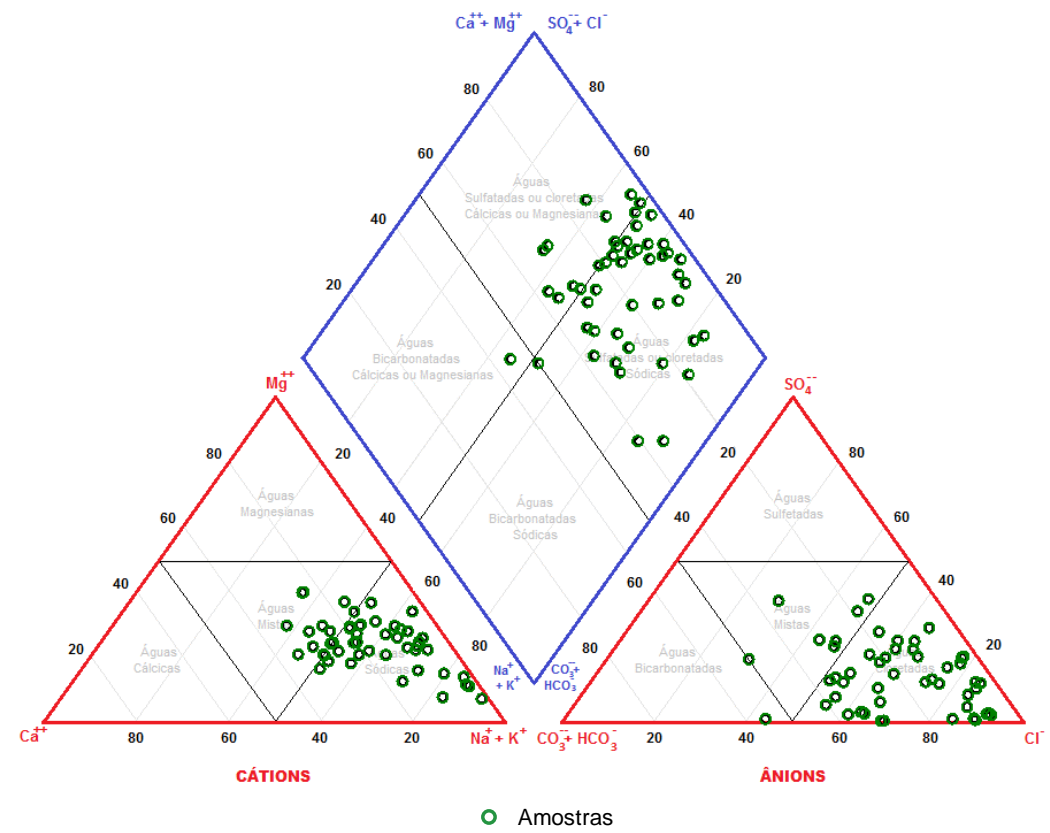

Figura 5 - Classificação iônica pelo Diagrama de Piper das águas subterrâneas na área de estudo Figure 5 - Ionic Classification in Piper of groundwater in the area of study

\section{CONSIDERAÇÕES FINAIS}

A análise fatorial permitiu classificar as variáveis de maior significância na qualidade das águas, priorizando aquelas relacionadas com a salinidade, associada às características geológicas da área. A análise de agrupamento classificou os poços em função da qualidade das águas, em três classes (grupos); mostrando as variações significativas.

A análise fatorial aplicada a doze atributos físico-químicos das águas subterrâneas, mostrou que três componentes respondem por aproximadamente $86 \%$ da variância total: o primeiro como indicador de salinidade e elementos nitrogenados, representado por sete atributos $\left(\mathrm{K}^{+}, \mathrm{Ca}^{+2}, \mathrm{Mg}^{2+}, \mathrm{N}-\mathrm{NO}_{3}\right.$, dureza, CE e STD); o segundo, como indicador da alcalinidade $(\mathrm{pH}$, bicarbonato e alcalinidade); e o terceiro, como indicador de salinidade $\left(\mathrm{Cl}^{-}, \mathrm{Na}^{+}, \mathrm{CE}\right.$ e STD) das águas subterrâneas.

A análise de agrupamento multivariada, aplicada tanto aos atributos do primeiro componente da análise fatorial, quanto ao do segundo e terceiro, apresentou dendrogramas com formação de três grupos, compostos individualmente por amostras com diferentes faixas de concentrações.

Os dendrogramas gerados pelo agrupamento dos atributos do primeiro fator indicaram três tipos de água que podem ser destinadas para diversos fins. $\mathrm{O}$ Grupo 1 representa águas de qualidade intermediária, com presença de compostos nitrogenados em 35\% das amostras sendo, portanto, essas águas com valores anômalos restritas ao consumo humano. $\mathrm{O}$ Grupo 2 mostrou-se com águas de melhor qualidade, podendo todas elas serem destinadas principalmente ao consumo 
humano. O Grupo 3 é representado por águas de menor qualidade, tendo seu uso mais restrito.

Os dendrogramas gerados pelo agrupamento dos atributos do segundo fator indicaram três tipos de água. O Grupo 1 apresentou 100\% das águas ácidas (pH $<7)$. Os Grupos 2 e 3 mostraram-se as águas de melhor qualidade em relação ao grupo 1, com 85 e 71\% de águas ácidas. A acidez nas águas dos poços é provavelmente associada ao Aquífero Barreiras e a introdução de águas recentes e poluídas no aquífero.

Os dendrogramas gerados pelo agrupamento dos atributos do terceiro fator indicaram três tipos de água. Os Grupos 1 , 2 e 3 são caracterizados por águas de salinidade intermediária, baixa e alta, respectivamente. A concentração de sais nas águas pode ser produzida por diversos fatores, sendo os mais prováveis a dissolução e o processo de evaporação.

A predominância de águas cloretadas sódicas na área está potencialmente relacionada às águas marinhas, aerossóis e à evaporação e é independente do período de recarga do aquífero. O sódio com menor concentração em relação ao cloreto é causado pela remoção através de troca iônica e ocorre normalmente no Aquífero sedimentar.

Os resultados mostraram que o uso da análise fatorial, associada a análise de agrupamento multivariada, é importante no monitoramento e suporte a gestão da qualidade das águas subterrâneas, principalmente em regiões semiáridas, que são de alta vulnerabilidade socioambiental.

O presente estudo contribuiu para subsidiar ações futuras, indispensáveis a uma gestão mais adequada desse recurso hídrico natural predominante na área, além de tentar promover um sistema estratégico, que possa ser utilizado para a demanda atual ou futura do município. Em regiões costeiras, a gestão é ainda mais emergencial devido aos riscos da ocorrência de intrusão salina em decorrência da sobrexplotação.

Ressalta-se a necessidade de um gerenciamento e monitoramento das águas subterrâneas da área, no sentido de localizar as possíveis fontes contaminantes, para que não só a qualidade, mas também a disponibilidade deste recurso possa ser considerada como um aproveitamento estratégico e sustentável para o município de Fortaleza.

\section{AGRADECIMENTOS}

Os autores agradecem a CAPES/REUNI, pela bolsa de Doutorado concedida a primeira autora durante o período de março/2009 a fevereiro/2013 no curso de Pós-graduação em Geologia da Universidade Federal do Ceará.

\section{REFERÊNCIAS}

ALMEIDA, J. R. F. de; FRISCHKOM, H. Agrupamento da qualidade da água de poços de um pequeno aquífero aluvial: estudo de caso da bacia do riacho Forquilha em Quixeramobimce/Brasil. Revista AIDIS de Ingeniería y Ciencias Ambientales: Investigación, desarrollo y práctica. v. 8, n. 1, p. 114-130, 2015.

ANDRADE, E. M.; SILVEIRA, S. S.; AZEVEDO, B. M. Investigação da estrutura multivariada da evapotranspiração na região centro sul do Ceará pela análise de componentes principais. Revista Brasileira de Recursos Hídricos, Porto Alegre, v. 8, n. 1, p. 39-44, 2003.

ANDRADE, E. M.; PALÁCIO, H. A.; SOUZA I.H.; OLIVEIRA L. R. A.; GUERREIRO, M.J. Land use effects in groundwater composition of an alluvial aquifer (Trussu River, Brazil) by multivariate techniques. Environmental Research, v. 106, p. 170-177, 2008.

ANDRADE, E. M; LOPES, F. B.; PALÁCIO, H. A. Q.; NASCIMENTO, D. do; ALEXANDRE, D. M. B. Land use and groundwater quality: The case of Baixo Acaraú 
Irrigated Perimeter, Brazil. Revista Ciência Agronômica, Fortaleza, v. 41, n. 2, p. 208-215, 2010.

ARAÚJO, A. O.; MENDONÇA, L. A. R.; LIMA, M. G. de S.; FEITOSA, J. V.; SILVA, F. J., NESS, R. L. L; FRISCHKORN, H.; SIMPLÍCIO, A. A. F.; KERNTOPF, M. R. Modificações nas propriedades dos solos de uma área de manejo florestal na Chapada do Araripe. Revista Brasileira Ciência do Solo, v. 37, p. 754-762, 2013.

BRASIL. Ministério da Saúde. Portaria $n^{\circ}$ 2914 de 12 de dezembro de 2011. Estabelece normas e o padrão de potabilidade da água destinada ao consumo humano. Diário Oficial da União, Brasília, 14 dez. 2011. 34 p.

BRITO, L. T. L.; SILVA, A. de S.; SRINIVASAN, V. S.; GALVÃO, C. de O.; GHEYI, H. R. Uso de análise multivariada na classificação das fontes hídricas subterrâneas na bacia hidrográfica do Salitre. Revista Engenharia Agrícola, Jaboticabal, v. 26, n. 1, p. 36-44, 2006.

CALLEGARI-JACQUES, S. M. Bioestatística: princípios e aplicações. Porto Alegre: Artemed, 255 p., 2003.

CAVALCANTE, I.N. Fundamentos hidrogeológicos para a gestão integrada de recursos hídricos na Região Metropolitana de Fortaleza, Estado do Ceará. Tese (Doutoramento em Recursos Minerais e Hidrogeologia). Universidade de São Paulo. 1998. $153 \mathrm{p}$.

CLOUTIER, V.; LEFEBVRE, R.; THERRIEN, R.; SAVARD, M. M. Multivariate statistical analysis of geochemical data as indicative of the hydrogeo chemical evolution of groundwater in a sedimentary rock aquifer system. Journal of Hydrology, v. 353, p. 294-313, 2008.

FERNANDES, F. B. P.; ANDRADE, E. M. de.; FONTENELE , S. de B.; MEIRELES, A. C. M.; RIBEIRO, J. A. Análise de agrupamento como suporte à gestão qualitativa da água subterrânea no semiárido cearense.
Revista Agro@mbiente On-line. Roraima, v. 4, n. 2, p. 86-95, 2010.

FERREIRA, D. F. Análise multivariada. Lavras, Minas Gerais, 394 p., 1996.

GOMES, M.C.R. Análise situacional qualitativa sobre as águas subterrâneas de Fortaleza, Ceará/Brasil como subsídio à gestão dos recursos hídricos. Tese (Doutoramento em Hidrogeologia). Universidade Federal do Ceará. 2013. 213 p

HAIR JR., J. F.; ANDERSON, R. E.; TATHAN, R. L.; BLACK, W. C. Multivariate data analysis. New Jersey, Prentice Hall, 928 p., 1998.

HOFFMANN, R. Componentes principais e análise fatorial. Piracicaba, 25 p. (Série Didática, 76)., 1992.

HOUNSLOW, A. W. Water quality data: analysis and interpretation. Lewis Publishers New York. Boca Raton, 395 p. 1995.

MACHADO, C. J. F.; SANTIAGO, M. M. F.; FRISCHKORN, H.; MENDES FILHO, J. Clustering of groundwaters by Q-mode factor analysis according to their hydrogeochemical origin: A case study of the Cariri Valley (Northern Brazil) wells. Water SA (on-line). v. 34, n. 5, p. 651-656, 2008.

MANLY, B. F. J. Multivariate statistical methods. 2.ed. London, Chapman e Hall, 215 p., 1998.

MOBUS, G. Qualigraf: software para interpretação de análises físico-químicas, versão Beta. Fundação Cearense de Meteorologia e Recursos Hídricos FUNCEME. Fortaleza. Disponível em: http://www.funceme.br. Acessado em: 20mar/2016. 2014.

PINA, A. P. S. A. de. Fundamentos hidrogeoquímicos aplicados na Bacia Hidrográfica de Santa Cruz, Ilha de Santiago - Cabo Verde, como instrumento para a gestão de recursos hídricos, 2012. 150 p. Dissertação (Mestrado em Geologia). 
Universidade Federal do Ceará.

POHLING, R.; SANTIAGO, M. F.; TORQUATO, J. R.; GARRETT, L. Estudo da qualidade da água de Fortaleza. In: POHLING, R. Estudos Hidrológicos do Nordeste. Fortaleza: BNB, v. 3, p. 7-72. 1981.

SALGADO, E. V.; ANDRADE, E. M. de, FONTENELE, S. de B., MEIRELES, A. C. M. Similaridade das variáveis hidroquímicas com o uso da análise multivariada, na Bacia do Salgado, Ceará. Revista Caatinga, v. 24, n. 3, p. 158-166, 2011.

SANTOS, A. C. Noções de Hidroquímica. In: FEITOSA, F. A. C.; MANOEL FILHO, J.; FEITOSA, E. C.; DEMETRIO, J. G. A. Hidrogeologia: conceitos e aplicações. Rio de Janeiro: CPRM e LABHID, 3. ed. revisada e ampliada, p. 325-357. 2008.
VEGA, M.; PARDO, R.; BARRADO, E.; DEBÁN, L. Assessement of seasonal and polluting effects on the quality of river water by exploratory data analysis. Water Research. v. 32, n. 12, p. 3581-3592, 1998.

VIDAL, A. C.; KIANG, C. H. Caracterização hidroquímica dos aquíferos da bacia de Taubaté. Revista Brasileira de Geociências. Curitiba, v. 32, n. 2, p. 267-276, 2002.

YIDANA, S. M.; OPHORI, D.; BANOENGYAKUBO, B. A multivariate statistical analysis of surface water chemistry data. The Ankobra basin, Ghana. Journal of Environmental Management, n. 86, p. 80-87, 2008. 